\title{
Self-Care Behavior Profiles With Arteriovenous Fistula in Hemodialysis Patients
}

\author{
Clemente Neves Sousa, PhD, RN ${ }^{1,2}\left(\mathbb{D}\right.$, Patrícia Marujo, RN ${ }^{3}$, \\ Paulo Teles, $\mathbf{P h D}^{4}$, Marta Nunes Lira, $\mathbf{R N}^{5}$, \\ Vanessa Filipa Ferreira Dias, MPH, RN ${ }^{6,7}$, \\ and Maria Eulália Leite Mota Novais, $\mathbf{R N}^{3}$
}

\begin{abstract}
Patients with end-stage renal disease should be educated and trained to take care of their own arteriovenous fistula (AVF) with the purpose of developing self-care behaviors concerning vascular access. This was a prospective and observational study. We designed this research to identify clinically meaningful self-care behavior profiles in hemodialysis (HD) patients, and it was carried out in a private dialysis unit in the Lisbon region, Portugal, involving I0I patients. The proportion of male patients was $66.3 \%$, the mean age was 60.9 years, and the frequency of self-care behaviors was 7 I \%. Cluster analysis based on the subscale scores grouped patients in two clusters named "moderate self-care" and "high self-care." Those profiles exhibit significant differences concerning gender, education, employment, dialysis vintage, AVF duration, and information on care with the AVF. Identification of self-care-behavior profiles in HD patients with AVF enables one to adjust education programs to the patients' characteristics.
\end{abstract}

\section{Keywords}

hemodialysis, vascular access, arteriovenous fistula, self-care, behaviors

\section{Introduction}

The arteriovenous fistula (AVF) is considered the best vascular access for hemodialysis (HD). Development of selfcare behaviors with the AVF allows maintaining the access in good condition, prevents complications related to vascular access, and can contribute to AVF patency (Kukita et al., 2015; NKF-K/DOQI, 2006; Tordoir et al., 2007). Patients with end-stage renal disease (ESRD) should be educated and trained to take care of their own AVF, with the purpose of developing self-care behaviors with their vascular access (Sousa et al., 2014; Sousa et al., 2017). Furthermore, AVFcaring patients are more likely to identify complications with the vascular access.

Identification of HD patients' characteristics who are or who are not able of caring for the AVF is very important to adjust the education program type and duration. Different proportions of HD patients actually carry out self-care behaviors with the AVF, between $28.1 \%$ and $100 \%$ (Sousa et al., 2017). In another study with 30 ESRD patients on HD, $97.7 \%$ had inadequate self-care behaviors with the AVF (Pessoa \& Linhares, 2015). We are not aware of any work in the literature providing the identification of patients' characteristics that enable them to develop higher levels of self-care behaviors with the AVF. As patients with ESRD have different profiles regarding such characteristics, understanding the relationship between those profiles and self-care behaviors is very important for the implementation of education programs. Our study was designed to identify clinically meaningful self-care behavior profiles in HD patients.

\footnotetext{
'Center for Health Technology and Services Research Faculty of Medicine (CINTESIS), Porto University, Portugal

${ }^{2}$ Nursing School of Porto, Portugal

${ }^{3}$ Nursing School of Lisbon, Portugal

${ }^{4}$ School of Economics and LIAAD-INESC Porto, Porto University, Portugal

${ }^{5}$ Federal University of Pernambuco, Recife, Brazil

${ }^{6}$ Institute of Health Sciences, University Católica Porto, Portugal

${ }^{7}$ Unidade de Saúde Familiar Santo André de Canidelo, Vila Nova de Gaia, Portugal

Corresponding Author:

Clemente Neves Sousa, Nursing School of Porto, Rua Dr António Bernardino de Almeida, 4200-072 Porto, Portugal.

Email: clementesousa@esenf.pt
} 


\section{Method}

\section{Study Design}

This was a prospective and observational study in a dialysis unit involving patients who used an AVF for HD. The study started after approval by the institution ethics committee.

\section{Study Setting and Population}

The study was carried out in a private dialysis unit in the Lisbon region, Portugal. The criteria for participants to be eligible for the study were as follows: participants should be 18 years or older, have an AVF duration on HD greater than 6 months, have inexistence of memory problems, and be medically stable. Exclusion criteria of patients were double access vascular (central venous catheter and AVF) and grafts as vascular access. Participants were invited for the study. Those with no interpretation problems completed the questionnaire autonomously, and those with problems were assisted by the researcher. A total of 111 patients were included, and 10 patients refused to participate.

\section{Data Collection and Instrument}

The data were collected between January and February 2016. Information concerning demographic characteristics (age, gender, education, employment, marital status) and clinical characteristics (ESRD etiology, dialysis vintage, previous AVFs, AVF duration, information on care with the AVF) was collected from a questionnaire designed by the authors. Information concerning self-care behaviors with the AVF was collected from the Scale of Assessment of SelfCare Behaviors with Arteriovenous Fistula in Hemodialysis (ASBHD-AVF) (Sousa et al., 2015). This scale has 16 items in two subscales: subscale 1-Management of Signs and Symptoms (6 items) and subscale 2-Prevention of Complications (10 items). Responses to each item are based on a 5-point Likert-type scale. Higher scores show patients' higher frequency of self-care with the AVF. Memory problems were assessed by the Six-Item Cognitive Impairment Test (6CIT), Portuguese version (Apóstolo, Paiva, Silva, Santos, \& Schultz, 2017).

\section{Statistical Analysis}

Quantitative variables were described by the mean and standard deviation. The distribution of categorical variables was described by proportions.

The overall scale is most likely unable to uncover the different patterns exhibited by the two subscales, and thus, we chose to analyze each subscale separately. A $10 \% p$ value was considered statistically significant. Hierarchical clustering with Ward's method was used for cluster analysis.

Analysis was performed with the Statistical Package for the Social Sciences software (version 23.0; IBM Co., USA) and with the R language (version 3.3.1, R Foundation for Statistical Computing, Austria).

\section{Results}

\section{Patient Characteristics}

This study involved 101 patients with AVF on HD treatment (Table 1). Two thirds of the patients were male $(66.3 \%)$. Concerning sociodemographic characteristics, the mean age was 60.9 years (with an $S D$ of 13.4), most ages ranged between 50 and 70 years, and few patients were less than 50 years old. The proportion of married patients was $51.4 \%, 39.6 \%$ of the patients had a 4-year education, and $20.8 \%$ had a college degree. Most patients (58.4\%) were retired.

Concerning the study clinical characteristics, $26.7 \%$ of the patients had hypertension, and $52.5 \%$ were in HD treatment for more than 5 years. The fistula duration mean was 71.3 months (with an $S D$ of 78.3 months; range: 6-432 months), but the median duration was 48 months (i.e., $50 \%$ of the patients had the fistula for 48 months or less). A small number of patients had a previous fistula (25.6\%), 20.4\% had two AVFs, and 5.2\% had three or more AVFs (Table 1). Information on care with the fistula was provided by the nephrologist, nurse, doctor, and no one in $50.5 \%, 28.7 \%, 4 \%$, and $15.8 \%$ of the patients, respectively.

\section{Self-Care Behavior Profiles}

The description of fistula self-care behaviors for the overall scale and the subscales is provided in Table 2.

The proportion of patients who performed self-care behaviors with the fistula was $71 \%$. However, analysis of the two subscales shows that patients performed less self-care behaviors concerning the Prevention of Complications subscale than concerning the Management of Signs and Symptoms subscale $(63.9 \%$ and $82.8 \%$, respectively). The percentage below the mean was $49.5 \%$ and $31.7 \%$, respectively.

Cluster analysis based on the subscale scores grouped patients in a two-cluster solution (Table 3). Cluster 1 is characterized by "moderate self-care" as the mean scores of the Management of Signs and Symptoms subscale and of the Prevention of Complications subscale were $72.4 \%$ and $51.2 \%$, respectively, whereas cluster 2 is characterized by "high selfcare" as the mean scores of the two subscales were respectively very high $(91.1 \%, p=.000)$ and high $(74.2 \%, p=.000)$.

Clusters 1 and 2 lead to different patient profiles as they exhibit significant differences concerning gender, education, employment, dialysis vintage, AVF duration, and information on care with the AVF (the remaining variables did not show significant differences). As displayed in Table 3, the comparison of both clusters shows that cluster 1 is mainly characterized by a larger proportion of male patients $(80.0 \%, p=$ $.009)$, a higher education level $(31.1 \%, p=.069)$, a larger proportion of employed patients and a smaller proportion of 
Table I. Sample Descriptive Measures.

\begin{tabular}{lc}
\hline & All patients \\
$(n=10 I)$
\end{tabular}

Note. $\mathrm{M}=$ male; $\mathrm{F}=$ female; ESDR = end-stage renal disease;

$\mathrm{AVF}=$ arteriovenous fistula.

retired patients ( $42.2 \%$ and $44.4 \%$, respectively, $p=.014$ ), shorter dialysis vintage $(p=.086)$, lower AVF duration $(61.4 \%, p=.053)$, and a lower proportion of patients whose information on care with the AVF was provided by the nephrologist $(40.0 \%, p=.074)$.

\section{Discussion}

We are not aware of any study on self-care-behavior profiles in hemodialysis patients with AVF. Very few studies analyzed the frequency of self-care behaviors (Ozen et al., 2017; Sousa et al., 2017), and only another one identified the variables affecting that frequency (Sousa et al., 2017). Our study assessed which patients' characteristics are clinically meaningful in the identification of AVF self-care-behavior profiles.

The frequency of self-care behaviors with the AVF was $71 \%$ (minimum of $28.1 \%$ and maximum of $96.6 \%$ ). Concerning the subscales, patients exhibit higher frequencies of self-care behaviors in the Management of Signs and Symptoms subscale than in the Prevention of Complications subscale ( $82.8 \%$ vs. $63.9 \%$, respectively). Therefore, patients perform less self-care behaviors concerning AVF infection and thrombosis prevention (subscale 2). In a study with 335 ESRD patients in hemodialysis, 89 (29.6\%) and 127 (37.9\%) patients had some knowledge concerning AVF infection and thrombosis prevention, respectively (Ozen et al., 2017). A very large number of patients had no knowledge about Prevention of Complications with the AVF, and consequently, they did not carry out such self-care behaviors. In a sample of 30 ESRD patients on HD, two patients $(6.7 \%)$ said they felt the thrill of the fistula (Pessoa \& Linhares, 2015) and, in another study, only one patient out of 21 assessed the thrill (Furtado \& Lima, 2006). In our study, $49.5 \%$ of the patients exhibited self-care behaviors below the mean. This emphasizes the relevance of implementing programs that can alert patients to the importance of self-care behaviors concerning AVF Prevention of Complications.

The identification of AVF self-care-behavior profiles in HD patients is one of the most relevant findings in this study. Two profiles were identified in our sample: "moderate selfcare" and "high self-care." The "moderate self-care" profile shows that patients in this cluster had high self-care behaviors in Management of Signs and Symptoms and moderate self-care behaviors in Prevention of Complications. This profile is mainly characterized by patients of male gender $(80 \%)$, with higher education, employed, with lower AVF duration and dialysis vintage, and being provided information, fewer times, about care with the AVF by the nephrologist. However, patients with "high self-care" profile exhibit very high self-care behaviors in Management of Signs and Symptoms and high self-care behaviors in the Prevention of Complications. This profile is mainly characterized by patients of female gender, with lower education, retired, with higher AVF duration and dialysis vintage, and being provided information, more often, about care with the AVF by the nephrologist.

Our results enabled us to identify the profiles of self-care behaviors with the AVF through patients' individual characteristics. Those profiles can help adjusting education programs to such characteristics, that is, the implementation of these programs in dialysis units should take into account patients' individual characteristics, AVF self-care behavior profiles and patients' ability to carry out self-care behaviors. It will be important to run prospective randomized studies in the future to investigate the impact of vascular access education programs on self-care profiles and to find out whether 
Table 2. Self-Care Behaviors With Arteriovenous Fistula.

\begin{tabular}{|c|c|c|c|}
\hline & Overall scale & $\begin{array}{c}\text { Management of Signs and Symptoms } \\
\text { (subscale I) }\end{array}$ & $\begin{array}{l}\text { Prevention of Complications } \\
\text { (subscale 2) }\end{array}$ \\
\hline \multicolumn{4}{|l|}{ Self-care behaviors (\%) } \\
\hline$M(S D)$ & $71.0(13.6)$ & $82.8(18.1)$ & $63.9(16.9)$ \\
\hline Minimum & 28.1 & 29.2 & 25.0 \\
\hline Maximum & 96.6 & 100.0 & 100.0 \\
\hline Percentage below mean & 44.6 & 31.7 & 49.5 \\
\hline First quartile & 62.5 & 75.0 & 52.5 \\
\hline Median & 71.9 & 87.5 & 65.0 \\
\hline Third quartile & 81.3 & 100.0 & 75.0 \\
\hline
\end{tabular}

Table 3. Cluster Description and Comparison.

\begin{tabular}{|c|c|c|c|}
\hline Variable & $\begin{array}{c}\text { Cluster I } \\
\text { Moderate self-care } \\
\quad(n=45)\end{array}$ & $\begin{array}{l}\text { Cluster } 2 \\
\text { High self-care } \\
\quad(n=56)\end{array}$ & $p$ value \\
\hline \multicolumn{4}{|l|}{ Scales } \\
\hline Subscale I, mean (SD) & $72.4(20.9)$ & $91.1(9.4)$ & .000 \\
\hline Subscale 2, mean (SD) & $51.2(14.4)$ & $74.2(10.7)$ & .000 \\
\hline Gender $(M) \%$ & 80.0 & 55.4 & .009 \\
\hline Age in years, mean $(S D)$ & $59.5(15.3)$ & $62.1(11.8)$ & .393 \\
\hline Marital status (\%) & & & .154 \\
\hline Married & 42.2 & 58.9 & \\
\hline Divorced & 8.9 & 8.9 & \\
\hline Widow & II.I & 14.3 & \\
\hline Single & 37.8 & 17.9 & \\
\hline Education (\%) & & & .069 \\
\hline$\leqslant 4$ years & 33.3 & 44.6 & \\
\hline $5-9$ years & 17.8 & 21.4 & \\
\hline $10-12$ years & 17.8 & 21.4 & \\
\hline College & 31.1 & 12.5 & \\
\hline Employment (\%) & & & .014 \\
\hline Employed & 42.2 & 16.1 & \\
\hline Unemployed & II.I & 14.3 & \\
\hline Retired & 44.4 & 69.6 & \\
\hline Student & 2.2 & 0.0 & \\
\hline ESRD etiology (\%) & & & .355 \\
\hline Arterial hypertension & 17.8 & 33.9 & \\
\hline Polycystic kidney & 13.3 & 12.5 & \\
\hline Glomerular & 13.3 & 10.7 & \\
\hline Other kidney disease & 40.0 & 32.1 & \\
\hline Dialysis vintage (\%) & & & .086 \\
\hline$\leqslant$ I years & 15.6 & 5.4 & \\
\hline $1-5$ years & 40.0 & 35.7 & \\
\hline$\geqslant 5$ years & 44.4 & 58.9 & \\
\hline AVF duration in months, mean $(S D)$ & $61.4(78.7)$ & $79.3(77.7)$ & .053 \\
\hline Number previous AVFs (\%) & & & .165 \\
\hline I AVF & 31.1 & 44.6 & \\
\hline 2 AVF & 68.9 & 55.4 & \\
\hline Information about care with AVF (\%) & & & .074 \\
\hline No one & 20.0 & 12.5 & \\
\hline Nephrologist & 40.0 & 58.9 & \\
\hline Nurse & 28.9 & 28.6 & \\
\hline
\end{tabular}

Note. $M=$ male; ESDR = end-stage renal disease; $\mathrm{AVF}=$ arteriovenous fistula. 
specific education programs should be designed for patients with a "moderate self-care" profile.

The significant differences between "moderate self-care" and "high self-care" profiles suggest that there are clinically meaningful subgroups (clusters). Replicating the cluster analysis with other independent and larger samples is required before assuming that the defined subgroups are stable and thereby meaningful in a clinical and empirical sense. This study should be considered as a first step in the identification of self-care-behavior profiles in HD patients with AVF.

\section{Conclusion}

We identified two self-care-behavior profiles in HD patients, namely "moderate self-care" and "high self-care." The "moderate self-care" profile mainly consists of male patients, with higher education level, employed, with shorter dialysis vintage, with lower AVF duration, and being provided information, fewer times, about care with the AVF by the nephrologist. However, the "high self-care" profile mainly consists of female patients, with lower education level, retired, with longer dialysis vintage, with higher AVF duration, and being provided information, more often, about care with the AVF by the nephrologist. Further studies are required to better identify self-care-behavior profiles. Furthermore, studying the impact of education programs on how patients acquire AVF self-care behaviors is also essential.

\section{Declaration of Conflicting Interests}

The author(s) declared no potential conflicts of interest with respect to the research, authorship, and/or publication of this article.

\section{Funding}

The author(s) received no financial support for the research, authorship, and/or publication of this article.

\section{ORCID iD}

Clemente Neves Sousa iD https://orcid.org/0000-0003-2654-0497

\section{References}

Apóstolo, J., Paiva, D., Silva, R., Santos, E., \& Schultz, T. (2017). Adaptation and validation into Portuguese language of the Six-Item Cognitive Impairment Test (6CIT). Aging \& Mental Health, 25, 1-6.

Furtado, A., \& Lima, F. (2006). Care of arteriovenous fistula by patients with chronic renal failure. Revista gaúcha de enfermagem, 27, 532-538.
Kukita, K., Ohira, S., Amano, I., Naito, H., Azuma, N., Ikeda, K., . . A Akizawa, T. (2015). 2011 update Japanese society for dialysis therapy guidelines of vascular access construction and repair for chronic hemodialysis. Therapeutic Apheresis and Dialysis, 19(Suppl. 1), 1-39.

National Kidney Foundation/Kidney Disease Outcomes Quality Initiative (NKF KDOQI). (2006). K/DOQI clinical practice guidelines in vascular access: 2006 update. American Journal of Kidney Diseases, 48(Suppl.), S176-S306.

Ozen, N., Tosun, N., Cinar, F., Bagcivan, G., Yilmaz, M., Askin, D., ... Zajm, E. (2017). Investigation of the knowledge and attitudes of patients who are undergoing hemodialysis treatment regarding their arteriovenous fistula. The journal of vascular access, 18, 64-68.

Pessoa, N., \& Linhares, F. (2015). Hemodialysis patients with arteriovenous fistula: Knowledge, attitude and practice. Escola Anna Nery, 19, 73-79.

Sousa, C. N., Apóstolo, J., Figueiredo, M., Dias, V., Teles, P., \& Martins, M. (2015). Construction and validation of a scale of assessment of self-care behaviors with arteriovenous fistula in hemodialysis. Hemodialysis International, 19, 306-313.

Sousa, C. N., Apóstolo, J. L., Figueiredo, M. H., Martins, M. M., \& Dias, V. F. (2014). Interventions to promote self-care of people with arteriovenous fistula. Journal of Clinical Nursing, 23, 1796-1802.

Sousa, C. N., Marujo, P., Teles, P., Lira, M., \& Novais, M. (2017). Self-care on hemodialysis: Behaviors with the arteriovenous fistula. Therapeutic Apheresis and Dialysis, 21, 195-199.

Tordoir, J., Canaud, B., Haage, P., Konner, K., Basci, A., Fouque, D., . . . Vanholder, R. (2007). EBPG on vascular access. Nephrology Dialysis Transplantation, 22(Suppl. 2), ii88-ii117.

\section{Author Biographies}

Clemente Neves Sousa, $\mathrm{PhD}, \mathrm{RN}$, is adjunct professor at Nursing School of Porto. Scientific coordinator of vascular access center (Grupo Estudos Vasculares - GEV). Areas of research interest are hemodialysis vascular access and end stage renal disease.

Patrícia Marujo, RN, is dialysis nurse in Nephocare.

Paulo Teles, $\mathrm{PhD}$, is professor at Economy University, Porto University.

Marta Nunes Lira, RN, master student at Federal University of Pernambuco, Recife, Brazil.

Vanessa Filipa Ferreira Dias, MPH, RN, PhD student at Institute of Health Sciences, University Católica Porto, Portugal.

Maria Eulália Leite Mota Novais, RN, is adjunct professor at Nursing School of Lisboa. 